\title{
Type I thoracoabdominal aortic aneurysm: Intercostal reimplantation by the "snake" technique
}

\author{
Delfina Fletcher-Sanfeliu, MD, PhD, ${ }^{\mathrm{a}}$ Alvaro García-Granero, $\mathrm{MD}, \mathrm{PhD},{ }^{\mathrm{b}}$ Cristina Rueda Muñoz, $\mathrm{MD},{ }^{\mathrm{a}}$ and \\ Ivan Martín-González, MD, PhD, ${ }^{a}$ Valencia, Spain
}

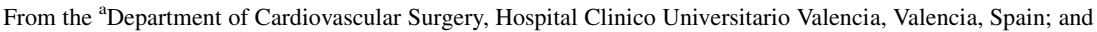
${ }^{\mathrm{b}}$ Department of General Surgery, Hospital Universitario y Politecnico La Fe, Valencia, Spain. Disclosures: Authors have nothing to disclose with regard to commercial support.

Received for publication July 15, 2017; revisions received Oct 9, 2017; accepted for publication Nov 9, 2017; available ahead of print Dec 14, 2017.

Address for reprints: Delfina Fletcher-Sanfeliu, MD, PhD, Department of Cardiovascular Surgery, Hospital Clínico Universitario of Valencia, Spain, Avda. Blasco Ibañez, 17, Valencia 46010, Spain (E-mail: delfletsan@gmail.com).

J Thorac Cardiovasc Surg 2018;155:1399-400

$0022-5223 / \$ 36.00$

Copyright (C) 2017 by The American Association for Thoracic Surgery

https://doi.org/10.1016/j.jtcvs.2017.11.019
}

Video clip is available online.

Paraplegia still remains a serious complication of thoracoabdominal aortic aneurysm (TAAA) open surgery. Several spinal cord adjuncts have been described to prevent this devastating sequel, such as intraoperative monitoring of spinal cord function by motor- and somatosensory-evoked potentials, cerebrospinal fluid drainage, regional spinal cord hypothermia, distal aortic perfusion, critical intercostal pairs (T7-L1) reimplantation, ${ }^{1}$ and systemic cooling to moderate or profound hypothermia, in addition to the importance of optimal hemodynamic management.

Well-known risk factors for paraplegia include the aortic crossclamp time and Crawford-type TAAA. The pathophysiology of spinal cord damage during TAAA repair is still poorly understood, and the collateral network concept described by Randall Griepp in 2007 should be highlighted. ${ }^{2}$

The aortic surgical community has discussed the impact of single arteries that contribute to spinal perfusion. The decision of reattachment techniques versus the permanent disconnection of intercostal pairs is still a matter of debate. ${ }^{3}$

The "snake" technique (ST) in open surgery for TAAA was described by a Bavarian group in 2007 and consists of reimplanting intercostal arteries into the aortic main graft by the use of a loop-shaped parallel graft to reduce spinal cord injury. ${ }^{4}$ We have created a video (Video 1 ) of high educational value of how to perform this parallel graft technique in a type I TAAA case. Written informed consent was obtained from the patient to film the surgical procedure.

The patient was 37-year-old man with a medical history of hypertension and a mechanical Bentall procedure performed in 2012 for a type A aortic dissection with postanoxic encephalopathy with good recovery. He underwent

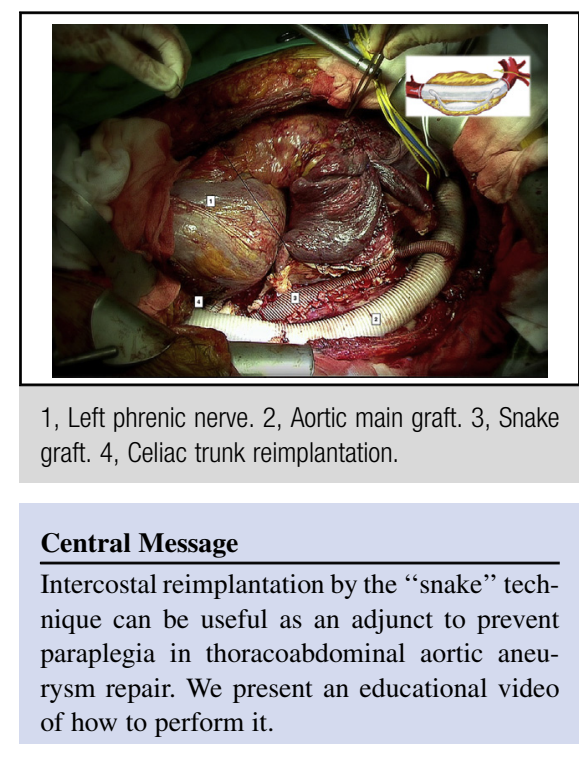

See Editorial Commentary page 1401.

an elective open aortic surgery 2 years later for a postdissection extent I TAAA. A cerebrospinal fluid drainage catheter was implanted preoperatively.

A Coselli 30-mm graft (Terumo Cardiovascular Systems, Elkton, Md) was used for aorta replacement from left subclavian artery until suprarenal segment with reattachment of superior mesenteric artery and celiac axis. A reverse elephant trunk was performed, in anticipation of a feasible aortic arch replacement in the future. Left femoro-femoral cannulation was used for partial cardiopulmonary bypass. On-pump time was 209 minutes, and proximal first clamp time was 37 minutes. Sequential aortic clamping was used to avoid blood steal phenomenon. Visceral hematic perfusion and cold crystalloid solution through renal arteries were used for visceral protection.

We performed the ST for T7-T12 intercostal pairs reimplantation with an 8-mm Dacron graft (Terumo Cardiovascular Systems, Elkton, Md), allowing a loop of continuous blood perfusion with a running suture with pledgeted interruption to achieve a more hemostatic suture. We directly perfused the intercostal graft during the distal aortic reconstruction to minimize spinal cord ischemia before reattachment of both graft endings to the main aortic graft.

The patient had a prolonged stay in the intensive care unit of 33 days due to acute respiratory distress syndrome with 


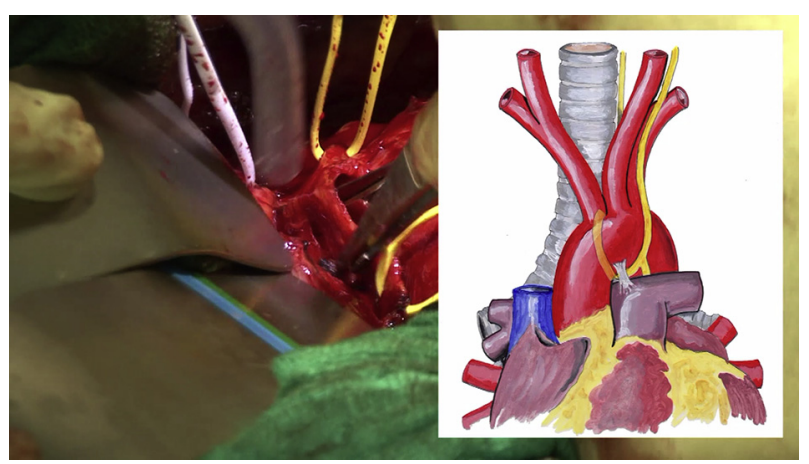

VIDEO 1. A "how-to-do-it" video showing the surgical technique of intercostal reimplantation by the snake technique in a type I thoracoabdomianl aortic aneurysm. Video available at: http://www.jtcvsonline.org/ article/S0022-5223(17)32691-0/fulltext.

the need for reintubation and tracheostomy. Moreover, he presented with transient acute renal failure without the need for renal therapy replacement. The entire length of hospital stay was 2 months, but he did not present signs of spinal cord damage, and he was discharged fully recovered.

Computed tomography angiography on postoperative month 6 showed patency of the snake graft. After 30 months of follow-up, patient remains asymptomatic and with no complications related to aortic surgery in the long-term imaging controls. Last computed tomography angiography showed patency of the intercostal graft with no signs of complication at 29th postoperative month.

The importance of preserving spinal cord vascularization has to be clarified because the long-term patency of reimplanted intercostal arteries is still unknown. ${ }^{5}$ Cardiovascular surgeons would benefit from advances in imaging of the spinal cord vascular supply to identify dominant arteries.

Even so, we advocate the ST may be a useful adjunct, ideally guided by intraoperative neuromonitoring, in preventing spinal cord ischemia in addition to other strategies employed for spinal cord protection, especially in those postdissection TAAA with decreased thrombus formation within the aneurysm sac. Patients with Marfan syndrome are at risk of aneurysmal degeneration of aortic tissue left behind and thus might be poor candidates for intercostal reimplantation requiring close imaging follow-up.

The ST is considered to have some advantages over a direct patch on main graft: it allows an end-to-side anastomosis without interruption of distal perfusion and a prompt direct hematic perfusion minimizing spinal cord ischemia time. ${ }^{4}$ It also avoids kinking of main aortic graft. Although this technique requires performing 3 anastomoses instead of 1, implying more risk of bleeding, anastomoses are more accessible during bleeding revisions. Otherwise, if aneurysmal degeneration of aortic tissue left behind occurs, it makes easier its isolation during reoperation. There is little information in literature regarding this technique, which may warrant further research.

The authors thank Mr Raul Sales Sevilla (audiovisual manager and scientific films director of University of Valencia) for the video edition and $\mathrm{Mr}$ Tomas Fletcher Benet for the original video illustrations.

\section{References}

1. Safi HJ, Miller CC III, Carr C, Iliopoulos DC, Dorsay DA, Baldwin JC. Importance of intercostal artery reattachment during thoracoabdominal aortic aneurysm repair. J Vasc Surg. 1998;27:58-66.

2. Griepp RB, Griepp EB. Spinal cord perfusion and protection during descending thoracic and thoracoabdominal aortic surgery: the collateral network concept. Ann Thorac Surg. 2007;83:S865-9.

3. Meffert P, Bischoff MS, Brenner R, Siepe M, Beyersdorf F, Kari FA. Significance and function of different spinal collateral compartment following thoracic aortic surgery: immediate versus long-term flow compensation. Eur J Cardiothorac Surg. 2014;45:799-804

4. Woo EY, Mcgarvey M, Jackson BM, Bavaria JE, Fairman RM, Pochettino A. Spinal cord ischemia may be reduced via a novel technique of intercostal artery revascularization during open thoracoabdominal aneurysm repair. J Vasc Surg. 2007; 46:421-6.

5. David N, Roux N, Douvrin F, Clavier E, Bessou JP, Plissonnier D. Aortic aneurysm surgery: long-term patency of the reimplanted intercostal arteries. Ann Vasc Surg. 2012;26:839-44. 